\title{
Exposure to traffic emissions throughout life and risk of breast cancer: the Western New York Exposures and Breast Cancer (WEB) study
}

\author{
Jing Nie $\cdot$ Jan Beyea $\cdot$ Matthew R. Bonner $\cdot$ Daikwon Han $\cdot$ \\ John E. Vena - Peter Rogerson - Dominica Vito - Paola Muti · \\ Maurizio Trevisan $\cdot$ Stephen B. Edge $\cdot$ Jo L. Freudenheim
}

Received: 18 January 2007/ Accepted: 22 June 2007/Published online: 14 July 2007

(C) Springer Science + Business Media B.V. 2007

\begin{abstract}
Objective We previously reported that total suspended particulates exposure (a measure of air pollution) at the time of birth was related to increased postmenopausal breast cancer risk. In this study, we examined breast cancer risk in relation to exposure to air pollution from traffic emissions throughout life.

Methods We conducted a case-control study of breast cancer. Participants were women, aged 35-79, residents of Erie and Niagara Counties. Cases had incident, primary, histologically confirmed breast cancer. Controls were randomly selected from the population, frequency-matched on
\end{abstract}

J. Nie $(\varangle) \cdot$ M. R. Bonner · D. Han · D. Vito .

M. Trevisan · J. L. Freudenheim

Department of Social and Preventive Medicine, School of Public Health and Health Professions, 270 Farber Hall, University at Buffalo, 3435 Main St., Buffalo, NY 14214, USA

e-mail: jingnie@buffalo.edu

J. Beyea

Consulting in the Public Interest, Lambertville, NJ 08530, USA

J. E. Vena

Department of Epidemiology and Biostatistics, Arnold School of Public Health, University of South Carolina, Columbia, SC 29208, USA

P. Rogerson

Department of Geography, University at Buffalo,

Buffalo, NY 14214, USA

P. Muti

Department of Epidemiology, IFO-Italian National Cancer Institute Regina Elena, Roma, Italy

\section{S. B. Edge}

Department of Breast and Soft Tissue Surgery, Roswell Park Cancer Institute, Buffalo, NY 14263, USA age and race. Using lifetime residential histories, exposure to traffic emissions was modeled for each woman using her residence as a proxy. Estimates were calculated for residence at menarche, her first birth, and 20 and 10 years before interview. Unconditional logistic regression was used to calculate odds ratios (OR) and 95\% confidence intervals (CI).

Results Higher exposure to traffic emissions at the time of menarche was associated with increased risk of premenopausal breast cancer (OR 2.05, 95\% CI 0.92-4.54, $p$ for trend 0.03); and at the time of a woman's first birth for postmenopausal breast cancer (OR 2.57, 95\% CI 1.16$5.69, p$ for trend 0.19$)$. Statistically significant associations were limited to lifetime non-smokers; there was a significant interaction between exposure at time of menarche and smoking for premenopausal women.

Conclusion Our findings add to accumulating evidence that early life exposures impact breast cancer risk and provide indication of potential importance of traffic emissions in risk of breast cancer.

Keywords Breast cancer - Lifecourse - Traffic emissions . Polycyclic aromatic hydrocarbons (PAHs)

\section{Introduction}

Breast cancer is a major cause of morbidity and mortality. In addition to established risk factors, it has been hypothesized that environmental exposures may also contribute to breast cancer risk [1-3]. Potentially important in explaining observed differences in breast cancer rates over time and between countries are exposures related to industrialization. Breast cancer risk tends to be higher in more industrialized countries than in less well developed countries [4, 5], as well 
as being higher in the urban (compared to the rural) areas of industrialized nations [6-8]. Incidence of breast cancer is particularly high in the Northeastern US [9], an area with heavy industrial and traffic emissions. While some of the observed geographic differences in rates are likely to be related to differences in distribution of known reproductive risk factors $[10,11]$, investigators have been interested in identifying potential carcinogens in the environment, including compounds in air that may also contribute to the observed variation. Traffic emissions are the major source of air pollutions in urban areas, and they contain many potential carcinogens, e.g., polycyclic aromatic hydrocarbons (PAHs) and benzene. Studies have found that exposure to traffic emissions may be associated with increased risk of total childhood cancer and childhood leukemia [12, 13]. However, there are few studies on traffic emissions and other cancers, although one study suggested that there was increased breast cancer risk among women living close to industrial sites and heavy traffic in Long Island, New York [14].

While there is increasing evidence that exposures in utero and in childhood may impact breast cancer risk [15], there has been little study of environmental exposures during this time period. However, there is evidence breast tissues may be more sensitive to carcinogens during childhood, particularly at the time of birth and during puberty [1, 16, 17]. Previously, we examined risk associated with exposure to total suspended particulates (TSP), an indicator of ambient air pollution. For each participant's residence at the time of her birth, menarche, and first birth, we estimated TSPs. We found that increased TSP exposure was associated with increased postmenopausal breast cancer risk for birth residence exposure [18].

We report here on a case-control study of breast cancer, the Western New York Exposures and Breast Cancer (WEB) study. Linking residential histories for participating cases and controls with measures of historical traffic emissions, we estimated exposures using a geographic traffic model for time periods of potential breast tissue sensitivity (i.e., at menarche, and at the time of a woman's first birth), and at other time windows in lifecourse (i.e., 20 and 10 years prior to interview).

\section{Materials and methods}

The WEB study included women who were aged 35-79 and residents of Erie and Niagara Counties in western New York State including the cities of Buffalo and Niagara Falls. Included were women with no previous history of cancer other than non-melanoma skin cancer. Details of the study have been described elsewhere [18, 19]. Briefly, cases had incident, primary, histologically-confirmed breast cancer. Controls were randomly selected from the residents of Erie and Niagara Counties and frequencymatched to cases on age and race. Those between the ages of 35 and 64 were selected from the New York State Department of Motor Vehicle list. Those 65 and over were identified through Health Care Finance Administration records. Among those determined eligible, response rates for the study were $72 \%$ (cases) and $63 \%$ (controls). All participants provided written informed consent, and the study protocol was approved by the Institutional Review Boards of the University at Buffalo and of all the participating hospitals.

Due to differences in risk factors for breast cancer by menopausal status, all analyses were stratified by menopausal status. In our study, a woman was defined as postmenopausal if her menses had ceased permanently and naturally. Also considered postmenopausal were women on hormone replacement therapy who were over age 55, women who had had a bilateral oophorectomy, women who had had a hysterectomy and were older than 50, women whose menses had ceased permanently due to radiation or other medical treatment and were older than 55 , and women over 55 whose menses had not ceased permanently.

\section{Data collection}

In-person interviews were used to collect data on potential breast cancer risk factors. Included were race, age, education, body mass index $\left(\mathrm{BMI}=\right.$ weight $(\mathrm{kg}) /$ height $\left.(\mathrm{m})^{2}\right)$, smoking history, usual diet during the period 12-24 months prior to interview, medical history, reproductive history, family history of breast cancer, previous benign breast disease, and occupational history.

Self-reported lifetime residential histories were also collected. Participants listed each of their residences for their entire lives, providing the addresses and the time periods when they lived at those addresses. For the addresses with incomplete information, an extensive search of available records, including the Polk Directory, was conducted to find as much missing data as possible.

Addresses were geocoded using ArcView 3.2 (ESRI, Inc., Redlands, CA), with GDT/Dynamap 2000 (GDT, Inc., Lebanon, NH) as the reference theme. ZP4 (Semaphore Co., Aptos, CA) software was used to correct and update the zip code for each address before the geocoding process. Geocoding was limited to participants' addresses in Erie and Niagara Counties. Our previous validation study showed good positional accuracy of the geocoded addresses in comparison to a global positioning system unit used as the gold standard to measure the latitude and longitude of the locations [20]. 
Exposure assessment

A geographic traffic exposure model, the Buffalo version of a model developed for the Long-Island Breast Cancer Study Project, was used to estimate historical residential exposure to traffic emission. The model estimated PAH exposure using benzo[a]pyrene $(\mathrm{BaP})$ as a surrogate for total PAH exposure. This emissions and meteorological dispersion model, along with its validation and calibration, has been described in detail previously [21, 22]. The data used for validation and calibration included PAH measurements carried out on a subset of study subjects, e.g., soil and carpet $\mathrm{BaP}$ concentrations, and PAH-DNA adducts in study subjects' blood, as well as measurements of carbon monoxide (CO) at an U.S. Environmental Protection Agency monitoring station. The authors found that, in three out of four of these comparisons, the model successfully predicted the relevant measurement [21, 22].

For use of the model in the Erie and Niagara Counties region, Long-Island data were replaced with region-specific meteorological and traffic data. Meteorological data were obtained from the National Climatic Data Center. The numbers of vehicles on roads in the two counties were obtained from the Greater Buffalo-Niagara Regional Transportation Council (GBNRTC) for the years from 1971 to 2002, and from the New York State Department of Transportation (NYSDOT) for the years from 1960 to 1975.

The traffic exposure model entails the choice of a scale factor corresponding to higher emissions at intersections, where vehicles are accelerating and decelerating [21]. This factor was obtained by calibrating the model to Erie and Niagara Counties regional air pollution data (carbon monoxide) collected by the U.S. Environmental Protection Agency. Carbon monoxide air concentration is highly correlated with PAH air concentration in cities $\left(R^{2}=0.5-0.8\right)$ [21].

With the region specific adjustments in place, the meteorological dispersion model was applied to estimate traffic emissions, particularly PAHs, emitted along the 54,494 road segments in the two study counties, producing exposure estimates for each residence for the participants specific to the time period of interest. Emission data per road segment were derived from historical data obtained for tailpipe emissions (Beyea J, Hatch M, Stellman SD, Gammon MD, unpublished data) and for number of vehicles on roads. The model produces relative rather than absolute estimates of exposure because the former are less sensitive to uncertainties in model parameters and because the model cannot really distinguish between traffic PAH pollutants and co-pollutants.

\section{Statistical methods}

Of the total of 1,170 cases and 2,116 controls in the WEB study, 1,068 cases and 1,944 controls provided information on lifetime residential history. There were a total of 20,862 individual addresses, among which 15,969 (77\%) were within Erie and Niagara Counties. This study was limited to those residences within Erie and Niagara Counties, with adequate information for geocoding and with consistent information on the year the participant moved in and out of the residential location. For these studies of traffic emissions, we were limited to historical data beginning in 1960; therefore, we limited our analysis here to residences in which study participants lived during or after 1960. Analyses were done separately for each of the time windows, i.e., at menarche, at the time of a woman's first birth, and 20 and 10 years prior to interview. We were not able to examine risk in relation to exposure at the time of the woman's own birth, because of these limitations in the availability of historical data.

To describe the distribution of the studied variables, means and standard deviations (SDs) were calculated for the continuous variables for cases and controls, and $t$-tests were used to compare means. $\chi^{2}$ tests were used for comparisons of categorical variables. Since the distribution of traffic emissions was skewed, all these values were natural $\log$ transformed. These exposure estimates were categorized into quartiles based on the distribution of traffic emissions among controls. The cutoffs of the traffic emissions varied based on menopausal status and time windows examined, i.e., premenopausal women at menarche analysis (7.65, 8.36, and 8.84), premenopausal women at first birth analysis $(6.42,7.41,8.16)$, postmenopausal women at first birth analysis (7.57, 8.35, 8.76 ), premenopausal women at 20 years prior analysis $(7.03,7.73,8.11)$, postmenopausal women at 20 years prior analysis $(6.94,7.72,8.14)$, premenopausal women at 10 years prior analysis $(5.40,6.15,6.75)$, and postmenopausal women at 10 years prior analysis $(5.49,6.29$, 6.82). Unconditional logistic regression was used to calculate odds ratios (OR) and 95\% confidence intervals (CI). To test for linear trend, we also examined a model with traffic emissions entered as a continuous variable. Breast cancer risk factors were adjusted for in the model, including the matching factors of age and race. Also included were education, BMI, age at menarche, age at menopause (for postmenopausal women only), age at first birth, number of births, family history of breast cancer, and previous benign breast disease. In addition to matching variables, i.e., age and race, a reduced model including education, age at first birth and year at interview was determined by removing covariates that did not alter the OR by more than $10 \%$. To test potential effect modification, analyses stratified by smoking status, and estrogen receptor (ER) and progesterone receptor (PR) status were also performed. 


\section{Results}

The number of cases and controls included in this study in periods of interest are shown in Table 1 . The study sample size varied among the time periods because of the lack of information about exposure in the earlier time periods and because of in-migration to the study region of study participants over time. We included all participants living in the two study counties at each time period.

The characteristics of subjects who were included in the analysis and those who were excluded from the study were compared in groups defined by case-control status and by menopausal status, for the different time periods of interest. In the excluded category were those who did not live in the two counties during the time period of interest, who lacked data regarding residence, or for whom the relevant time period (e.g., menarche) was before 1960. Women included in the study were somewhat younger than those who were excluded, particularly for the earlier time periods analyses, i.e., menarche and first birth analyses. This was the result of excluding women who had menarche or first birth before 1960. There were also some differences in the two groups for race, years of education, family history of breast cancer, history of previous benign breast disease, and reproductive factors. However, these differences generally were not of great magnitude. Further, when there was a difference, cases and controls tended to follow a similar pattern (data not shown).

Characteristics of breast cancer cases and controls by menopausal status are shown in Table 2 for the subsamples included in the analyses for exposure at menarche and at first birth (data for time periods of 20 years and 10 years prior to interview are not shown).

Crude and adjusted ORs for traffic emissions exposure are shown in Table 3. The association of risk of postmenopausal breast cancer with traffic emissions exposure at the time of menarche was not included because the sample size was too small. For premenopausal women, there was some indication of an increase in breast cancer risk for traffic emissions exposure at the time of menarche. $p$ for trend for the association was 0.03 , and the fourth quartile OR was 2.05 (95\% CI 0.92-4.54). For postmenopausal women, we found that traffic emissions exposure at the time when a woman first gave birth was associated with increased risk (OR 2.57, 95\% CI 1.16-5.69, $p$ for trend $0.19)$. There was no evidence that exposure to traffic emissions for any of the other time periods was associated with breast cancer risk.

When we stratified the subjects by smoking status (lifetime never and ever smokers), the observed increased risk associated with exposure to traffic emissions was limited to non-smokers (Table 4). Among non-smoking premenopausal women, exposure at the time of menarche was associated with breast cancer risk (OR 6.67, 95\% CI 1.74-25.67, $p$ for trend 0.01). Similarly, for non-smoking postmenopausal women, there was also increased risk (OR 6.23, 95\% CI 1.70-22.82, $p$ for trend 0.08). Among smokers, traffic emissions were not associated with risk. Controlling for smoking did not appreciably alter the results (data not shown). The interaction between smoking status and traffic emission exposure at menarche was statistically significant for premenopausal women ( $p=0.01)$, but did not reach formal statistical significance regarding exposure at the time of first birth among postmenopausal women $(p=0.06)$. Associations of traffic emissions exposure with breast cancer risk were not different in strata of ER and PR status (data not shown).

\section{Discussion}

We used a validated model to estimate exposure to traffic emissions based on residential location in potential critical time periods of breast cancer. We found increased risk of breast cancer among premenopausal women exposed to more traffic emissions at menarche and among postmenopausal women exposed at first birth; the observed increased risk was limited to non-smokers. Inconsistency in results between premenopausal and postmenopausal women may due to the differences in etiology for pre and postmenopausal breast cancer, or may relate to the fact that premenopausal women who were generally younger were exposed to less traffic emissions than postmenopausal women, because of the decreased trend of traffic emissions in later time periods. Although some of the $p$ 's for trend were statistically significant, these increased risks appeared

Table 1 Numbers of cases and controls included in the study in different time periods, WEB study, 1996-2001

\begin{tabular}{|c|c|c|c|c|}
\hline \multirow[t]{2}{*}{ Time period } & \multicolumn{2}{|l|}{ Cases } & \multicolumn{2}{|l|}{ Controls } \\
\hline & Premenopausal & Postmenopausal & Premenopausal & Postmenopausal \\
\hline Menarche & 187 & 52 & 347 & 76 \\
\hline First birth & 181 & 221 & 371 & 308 \\
\hline 20 years prior to interview & 210 & 672 & 413 & 1200 \\
\hline 10 years prior to interview & 258 & 717 & 501 & 1265 \\
\hline
\end{tabular}


Table 2 Characteristics of study sample by case-control status for subsamples included in the analyses for exposure at menarche and at the time of a woman's first birth, WEB study, 1996-2001

\begin{tabular}{|c|c|c|c|c|}
\hline \multirow[t]{2}{*}{ Characteristics* } & \multicolumn{2}{|c|}{ Premenopausal } & \multicolumn{2}{|c|}{ Postmenopausal } \\
\hline & Cases & Controls & Cases & Controls \\
\hline At menarche $(\mathrm{N})$ & 187 & 347 & 52 & 76 \\
\hline Age (years) & $43.8(4.0)^{*}$ & $43.0(3.9)^{*}$ & $49.4(3.0)^{*}$ & $47.3(3.0)^{*}$ \\
\hline Education (years) & $13.8(2.0)$ & $14.2(2.2)$ & $14.6(2.4)$ & $14.0(2.4)$ \\
\hline Race (\% of whites) & 96.3 & 96.3 & 92.3 & 90.8 \\
\hline Body mass index & $27.0(7.0)$ & $27.4(6.8)$ & $28.3(5.3)$ & $28.5(7.1)$ \\
\hline Nulliparous (\%) & 17.6 & 16.1 & 26.9 & 22.4 \\
\hline Age at menarche (years) & $12.6(1.6)$ & $12.7(1.6)$ & $12.9(1.5)$ & $13.1(1.8)$ \\
\hline Age at menopause (years) & l & l & $45.0(5.1)^{*}$ & $42.1(6.5)^{*}$ \\
\hline Family history of breast cancer ( $\%$ Yes) & $22.5^{*}$ & $9.8^{*}$ & 17.3 & 13.2 \\
\hline Previous benign breast disease ( $\%$ Yes) & $33.2 *$ & $19.6^{*}$ & 30.8 & 22.4 \\
\hline Smoking (packyears) & $7.6(11.4)^{*}$ & $5.1(9.0)^{*}$ & $8.6(15.5)$ & $12.0(15.8)$ \\
\hline Never Smoker $(\%)$ & 47.6 & 53.5 & 52.9 & 43.4 \\
\hline At first birth $(\mathrm{N})$ & 181 & 371 & 221 & 308 \\
\hline Age (years) & $44.5(4.7)$ & $44.2(4.6)$ & $57.0(6.0)^{*}$ & $54.5(6.1)^{*}$ \\
\hline Education (years) & $13.9(2.0)$ & $14.1(2.1)$ & $14.1(2.4)$ & $13.7(2.3)$ \\
\hline Race (\% of whites) & 95.6 & 96.0 & 93.7 & 94.2 \\
\hline Body mass index & $27.2(7.2)$ & $27.3(6.6)$ & $28.8(5.6)$ & $28.7(6.4)$ \\
\hline Age at menarche (years) & $12.5(1.4)$ & $12.7(1.6)$ & $12.4(1.6)$ & $12.5(1.7)$ \\
\hline Age at menopause (years) & l & l & $48.5(4.7)^{*}$ & $46.9(5.9)^{*}$ \\
\hline Family history of breast cancer (\% Yes) & $21.0^{*}$ & $8.9^{*}$ & $20.4 *$ & $10.1 *$ \\
\hline Previous benign breast disease ( $\%$ Yes) & $35.4^{*}$ & $21.8^{*}$ & $38.5^{*}$ & $25.6^{*}$ \\
\hline Smoking (packyears) & $7.7(11.4)^{*}$ & $5.4(9.7)^{*}$ & $10.2(13.8)$ & $12.6(17.4)$ \\
\hline Never Smoker $(\%)$ & 45.3 & 53.9 & 38.2 & 38.6 \\
\hline
\end{tabular}

* Values shown are means (SD) unless noted otherwise. Two-sided comparisons of means between the cases and controls were computed by Student's $t$-test; comparisons of categories were with the $\chi 2$ test. Those with * are significantly different, $p<0.05$

to be nonmonotonic; further study is needed to exam the dose-response effect. Traffic emissions exposure in other time periods, including 20 or 10 years prior to interview, were not associated with breast cancer risk.

We found a striking difference for analyses stratified by smoking status. Our study suggests that among smokers whose exposure to the products of cigarette combustion may be already high, additional exposure from traffic may not make a difference. However, among non-smokers, increased traffic emissions exposure appeared to increase breast cancer risk.

Russo et al. [17] have hypothesized that in the period between menarche and a first birth when breast tissues are at a peak of cell replication and are less differentiated, breast tissue may be more susceptible to initiation by carcinogens. In previous analyses in the WEB study data, we found evidence of more clustering of premenopausal breast cancer cases than for controls for residence at earlier life, i.e., at birth and menarche [19]. We also found that TSP exposures at birth residence were associated with increased postmenopausal breast cancer risk [18]. These previous findings and those reported here add to the evidence that earlier life environmental exposure may play a role in breast cancer risk.

The model that we used to estimate traffic emissions was based on an estimation of BaP exposure, a PAH. Although studies have found that higher concentrations of PAHDNA adducts are present in human breast tissues of cancer cases than noncancer controls [23-25] and that higher levels of PAH-DNA adducts in blood were associated with increased risk of breast cancer [26], PAHs have not been strongly linked to breast cancer risk in epidemiological studies. Although cigarette smoking is one of the major sources of PAH exposure, most studies have not found an association between adult smoking and breast cancer risk [27]. In the WEB study, both active (unpublished data) and secondhand smoking [28] were not statistical significantly associated with the risk of breast cancer. There are, however, several studies that suggest higher breast cancer risk among those who initiate smoking at an early age [29-32]. These findings are consistent with our study, suggesting the potential importance of earlier life exposure. Most occupational 
Table 3 Exposure to traffic emissions throughout life and risk of breast cancer, WEB study, 1996-2001

\begin{tabular}{|c|c|c|c|c|}
\hline Quartiles of exposure & Cases & Controls & Adjusted OR $(\mathrm{CI})^{\mathrm{a}}$ & Adjusted OR $(\mathrm{CI})^{\mathrm{b}}$ \\
\hline \multicolumn{5}{|l|}{ At menarche } \\
\hline \multicolumn{5}{|l|}{ Premenopausal } \\
\hline 1: & 29 & 86 & 1.00 & 1.00 \\
\hline 2: & 48 & 86 & $2.01(0.93-4.36)$ & $1.86(0.83-4.15)$ \\
\hline 3: & 51 & 87 & $2.31(1.03-5.17)$ & $2.14(0.93-4.94)$ \\
\hline 4: & 56 & 83 & $2.05(0.92-4.54)$ & $2.07(0.91-4.72)$ \\
\hline$p$ for trend & & & 0.03 & 0.03 \\
\hline \multicolumn{5}{|l|}{ At first birth } \\
\hline \multicolumn{5}{|l|}{ Premenopausal } \\
\hline $1:$ & 45 & 91 & 1.00 & 1.00 \\
\hline 2: & 55 & 88 & $1.77(0.82-3.84)$ & $1.80(0.81-3.99)$ \\
\hline 3: & 39 & 94 & $0.90(0.39-2.11)$ & $0.78(0.33-1.86)$ \\
\hline 4: & 39 & 92 & $1.27(0.48-3.32)$ & $1.22(0.44-3.36)$ \\
\hline$p$ for trend & & & 0.74 & 0.82 \\
\hline \multicolumn{5}{|l|}{ Postmenopausal } \\
\hline 1: & 39 & 75 & 1.00 & 1.00 \\
\hline 2: & 66 & 73 & $2.09(0.96-4.54)$ & $2.08(0.93-4.65)$ \\
\hline 3: & 53 & 78 & $1.25(0.55-2.83)$ & $1.20(0.52-2.77)$ \\
\hline 4: & 62 & 75 & $2.57(1.16-5.69)$ & $2.58(1.15-5.83)$ \\
\hline$p$ for trend & & & 0.19 & 0.19 \\
\hline \multicolumn{5}{|l|}{20 years prior } \\
\hline \multicolumn{5}{|l|}{ Premenopausal } \\
\hline 1: & 54 & 101 & 1.00 & 1.00 \\
\hline 2: & 52 & 101 & $0.84(0.42-1.69)$ & $0.79(0.39-1.64)$ \\
\hline 3: & 65 & 104 & $1.48(0.76-2.90)$ & $1.48(0.74-2.99)$ \\
\hline 4: & 35 & 100 & 1.37 (0.64-2.92) & $1.29(0.59-2.82)$ \\
\hline$p$ for trend & & & 0.44 & 0.60 \\
\hline \multicolumn{5}{|l|}{ Postmenopausal } \\
\hline $1:$ & 186 & 294 & 1.00 & 1.00 \\
\hline 2: & 205 & 296 & $0.92(0.67-1.25)$ & $0.88(0.64-1.20)$ \\
\hline 3: & 148 & 299 & $0.91(0.66-1.26)$ & $0.89(0.64-1.24)$ \\
\hline 4: & 119 & 292 & $0.87(0.61-1.23)$ & $0.82(0.58-1.18)$ \\
\hline$p$ for trend & & & 0.82 & 0.65 \\
\hline \multicolumn{5}{|l|}{10 years prior } \\
\hline \multicolumn{5}{|l|}{ Premenopausal } \\
\hline 1: & 90 & 122 & 1.00 & 1.00 \\
\hline 2: & 85 & 125 & $0.89(0.50-1.58)$ & $0.83(0.46-1.49)$ \\
\hline 3: & 55 & 120 & $1.53(0.84-2.78)$ & $1.41(0.76-2.60)$ \\
\hline 4: & 22 & 124 & $1.58(0.71-3.54)$ & $1.49(0.65-3.43)$ \\
\hline$p$ for trend & & & 0.38 & 0.62 \\
\hline \multicolumn{5}{|l|}{ Postmenopausal } \\
\hline 1: & 256 & 312 & 1.00 & 1.00 \\
\hline 2: & 249 & 310 & $1.12(0.84-1.49)$ & $1.10(0.83-1.47)$ \\
\hline
\end{tabular}


Table 3 continued

\begin{tabular}{lcccc}
\hline Quartiles of exposure & Cases & Controls & ${\text { Adjusted OR }(\mathrm{CI})^{\mathrm{a}}}$ & ${\text { Adjusted OR }(\mathrm{CI})^{\mathrm{b}}}^{\mathrm{a}}$ \\
\hline 3: & 115 & 313 & $1.06(0.76-1.47)$ & $1.04(0.74-1.45)$ \\
4: & 81 & 310 & $0.85(0.58-1.22)$ & $0.80(0.55-1.17)$ \\
$p$ for trend & & & 0.32 & 0.22 \\
\hline
\end{tabular}

${ }^{a}$ Odds ratios and $95 \%$ confidence intervals adjusted for age, race, education, age at first birth, and year at interview

b Odds ratios and 95\% confidence intervals adjusted for age, education, race, BMI, age at menarche, age at menopause (for post-menopausal women only), age at first birth, number of births, family history of breast cancer, previous benign breast disease, and year at interview

Table 4 Exposure to traffic emissions throughout life and risk of breast cancer by smoking status, WEB Study, 1996-2001

\begin{tabular}{|c|c|c|c|c|c|c|c|c|}
\hline \multirow[t]{2}{*}{ Quartiles of exposure } & \multicolumn{4}{|c|}{ Non-smokers } & \multicolumn{4}{|c|}{ Ever smokers } \\
\hline & Cases & Controls & Adjusted OR & $p$ for trend & Cases & Controls & Adjusted OR & $p$ for trend \\
\hline \multicolumn{9}{|l|}{ At menarche } \\
\hline \multicolumn{9}{|l|}{ Premenopausal } \\
\hline 1: & 11 & 54 & 1.00 & & 18 & 32 & 1.00 & \\
\hline 2: & 24 & 44 & $4.89(1.34-17.83)$ & & 24 & 42 & $1.02(0.36-2.91)$ & \\
\hline 3: & 26 & 44 & $6.96(1.86-26.02)$ & & 25 & 43 & $1.02(0.33-3.18)$ & \\
\hline 4: & 26 & 40 & $6.67(1.74-25.67)$ & 0.01 & 30 & 42 & $0.80(0.27-2.36)$ & 0.87 \\
\hline \multicolumn{9}{|l|}{ At first birth } \\
\hline \multicolumn{9}{|l|}{ Premenopausal } \\
\hline 1: & 20 & 56 & 1.00 & & 25 & 35 & 1.00 & \\
\hline 2: & 30 & 44 & $3.17(0.98-10.24)$ & & 25 & 43 & $1.00(0.33-3.03)$ & \\
\hline 3: & 16 & 48 & $1.42(0.40-5.11)$ & & 23 & 46 & $0.60(0.18-2.00)$ & \\
\hline 4: & 13 & 48 & $2.06(0.44-9.73)$ & 0.24 & 26 & 44 & $0.82(0.23-2.92)$ & 0.52 \\
\hline \multicolumn{9}{|l|}{ Postmenopausal } \\
\hline 1: & 16 & 41 & 1.00 & & 22 & 34 & 1.00 & \\
\hline 2: & 30 & 28 & $4.20(1.22-14.44)$ & & 36 & 45 & $1.21(0.43-3.41)$ & \\
\hline 3: & 13 & 25 & $1.89(0.47-7.61)$ & & 40 & 53 & $0.86(0.30-2.46)$ & \\
\hline 4: & 25 & 24 & $6.23(1.70-22.82)$ & 0.08 & 37 & 51 & $1.35(0.47-3.83)$ & 0.85 \\
\hline
\end{tabular}

Odds ratios and 95\% confidence intervals adjusted for age, race, education, age at first birth, and year at interview

studies have not supported an association between PAH exposure and increased breast cancer risk [33]; the number of cases in most of these studies is very small. In a study by Petralia et al. [34], PAHs were only associated with increased cancer risk among those with ER positive breast cancer. In our study, the associations of traffic emissions and breast cancer did not appear to be different by ER and PR status. In a study on Long Island, New York, highdensity traffic (a major source of PAH exposure) was found to be associated with a non-significant increase in breast cancer risk in one of the two study counties [14]. It is important to note that there are numerous other potential carcinogens in traffic emissions as well as PAHs. It is not possible, of course, in the context of this study, to distinguish the various components of the traffic emissions.

Traffic emissions have been linked to increased risk of total childhood cancer and childhood leukemia [12, 13]. The methods used for estimating traffic emissions in many previous studies have been based on aggregate traffic density data and/or proximity analysis. In some studies, only traffic density was used as the exposure measurement [12, 35-38], and in others, distance-weighted traffic density was used [13, 39-41]. These measures do not take into account meteorological conditions and the excess emissions at intersections and during engine warm-up, which may also be important sources of variation in exposure. Another study used monitored benzene data as a marker of traffic exposure [42]. Although all these methods provide some indication of total traffic emissions, with geographic modeling to incorporate GIS data, it is possible to model quantitative individual exposure estimates [43].

Although use of a geographic traffic model is a novel way to reconstruct historical traffic exposures, confidence in its suitability for use in an epidemiologic study requires comparison with field data. As discussed earlier, the model we used was validated and calibrated using both spatial and 
temporal data collected on Long Island and adapted to our study area.

The geographic model does have limitations. For instance, it does not consider the fact that the exposure estimate in each residence is not merely determined by traffic emissions and wind patterns but is also affected by the configuration of the street and buildings-the so-called street canyon effect [44]. The formation of a street canyon vortex may lead to recirculation of the pollutant, thus potentially increasing the pollutant level in the residence. However, neglect of street canyon effects may not have much impact on traffic exposure estimates in our study area, because the effect is strongest for locations with row housing, and such housing was rare. Another potential issue is historical changes in the road network. In spite of the fact that traffic road structure may change over time, we did not include an algorithm to "remove" any road sections from the network in backwards extrapolation. In addition, in this study, we ignored the effect of traffic emission sources from areas outside the two study counties. Since the study region is bounded by Lake Erie on one side and a suburban or rural area with very low traffic flow on all the other sides, this omission should have little effect on estimates. Additional measurement error might have been introduced because our exposure estimates did not account for exposure to traffic emissions while away from home. Our assumption here is that residential exposure would be a proxy for the majority of exposures, particularly in early life. Another possible important source of ambient air pollution and exposure to combustion products that we were unable to model in the current study is industrial emissions. Industrial emissions may be particularly important in terms of early life exposure. In the western New York region, industrial emissions would be a significant source of air pollution particularly before 1960 when steel industries were dominant in certain parts of the study areas. They would be less important after that time. Due to the limitations of the available data on traffic count, we were not able to include residences prior to 1960 in this study, preventing us from the examination of the association between traffic exposure at birth and breast cancer, although exposure at birth is another potentially important critical time window in terms of development of breast cancer.

As a case-control study design, this study may be subject to bias. Selection bias may be a concern, particularly for the time period analyses, where many participants could not be included. While we were not able to examine selection bias for the analyses of exposure in the past, we did examine it for current residence. There was some tendency for both participating cases and controls to have current residences closer to our study center than non-participants [19]. We did not find differences in the major characteristics between subjects who were included and excluded in the study, except that excluded women were older, particularly in the earlier time periods analyses, because women whose menarche or first birth was before 1960 were excluded. Recall bias is not likely in this study. At the time of study, participants were generally unaware of our study hypotheses and were unlikely to selectively report residential history differently by case-control status. There was likely misclassification from the self-reported residence information. In addition, there is misclassification in exposure from the model used to estimate traffic exposure; however, this misclassification is likely non-differential.

In this study, most participants provided their lifetime residential history; significant efforts were made to reconstruct historical traffic exposure. This allowed us to examine the relationship between breast cancer and traffic emissions in different time windows potentially critical to breast tissue development and to breast cancer.

Our study population was relatively stable with regard to residence. Approximately $77 \%$ and $82 \%$ of the participants lived in the study area at the time of menarche and first birth, respectively. Women, on average, moved six times in their lifetime. Thus, the exposure estimates for each time period are not limited to a single slice of time but rather are representative of a longer time period. The examination of cumulative traffic exposure may be of value in better understanding a relation, if any, with traffic exposure and risk and to capture the changes of exposure due to moving.

In summary, our study found evidence of increased breast cancer risk among premenopausal women exposed to high traffic emissions during the time of menarche and among postmenopausal women with high traffic exposure at the time of their first birth. This increased risk was limited to lifetime non-smokers. While these findings are subject to the limitations of epidemiologic observational studies, they are provocative in providing evidence both of the importance of early exposures and of the potential importance of a traffic-related environmental agent in risk of breast cancer. Further examination of traffic emissions in early life is warranted.

Acknowledgments This work has been supported in part by U.S. Army Medical Research Grants \#DAMD170010417 and \#DAMD179616202, NCI Grant \#1R21CA8713801, and NIH Grant \#5RO1CA092040.

\section{References}

1. John EM, Kelsey JL (1993) Radiation and other environmental exposures and breast cancer. Epidemiol Rev 15:157-162

2. Madigan MP, Ziegler RG, Benichou J, Byrne C, Hoover RN (1995) Proportion of breast cancer cases in the United States explained by well-established risk factors. J Natl Cancer Inst 87:1681-1685 
3. Laden F, Hunter DJ (1998) Environmental risk factors and female breast cancer. Annu Rev Public Health 19:101-123

4. Althuis MD, Dozier JM, Anderson WF, Devesa SS, Brinton LA (2005) Global trends in breast cancer incidence and mortality 1973-1997. Int J Epidemiol 34:405-412

5. Bray F, McCarron P, Parkin DM (2004) The changing global patterns of female breast cancer incidence and mortality. Breast Cancer Res 6:229-239

6. Blot WJ, Fraumeni JF Jr, Stone BJ (1977) Geographic patterns of breast cancer in the United States. J Natl Cancer Inst 59:1407-1411

7. Kelsey JL, Berkowitz GS (1988) Breast cancer epidemiology. Cancer Res 48:5615-5623

8. Nasca PC, Mahoney MC, Wolfgang PE (1992) Population density and cancer incidence differentials in New York State, 19781982. Cancer Causes Control 3:7-15

9. Kulldorff M, Feuer EJ, Miller BA, Freedman LS (1997) Breast cancer clusters in the northeast United States: a geographic analysis. Am J Epidemiol 146:161-170

10. Sturgeon SR, Graubard BI, Schairer C et al (2003) Populationdensity and county-level variation in breast cancer mortality rates among white women residing in the Northeastern and Southern United States. Cancer Causes Control 14:923-931

11. Sturgeon SR, Schairer C, Gail M et al (1995) Geographic variation in mortality from breast cancer among white women in the United States. J Natl Cancer Inst 87:1846-1853

12. Savitz DA, Feingold L (1989) Association of childhood cancer with residential traffic density. Scand J Work Environ Health 15:360-363

13. Pearson RL, Wachtel H, Ebi KL (2000) Distance-weighted traffic density in proximity to a home is a risk factor for leukemia and other childhood cancers. J Air Waste Manag Assoc 50:175-180

14. Lewis-Michl EL, Melius JM, Kallenbach LR et al (1996) Breast cancer risk and residence near industry or traffic in Nassau and Suffolk Counties, Long Island, New York. Arch Environ Health 51:255-265

15. Potischman N, Troisi R (1999) In-utero and early life exposures in relation to risk of breast cancer. Cancer Causes Control 10:561-573

16. Mole RH (1978) The sensitivity of the human breast to cancer induction by ionizing radiation. Br J Radiol 51:401-405

17. Russo J, Russo IH (2004) Molecular basis of breast cancer. Springer, Heidelberg, Germany

18. Bonner MR, Han D, Nie J et al (2005) Breast cancer risk and exposure in early life to polycyclic aromatic hydrocarbons using total suspended particulates as a proxy measure. Cancer Epidemiol Biomarkers Prev 14:53-60

19. Han D, Rogerson PA, Nie J et al (2004) Geographic clustering of residence in early life and subsequent risk of breast cancer (United States). Cancer Causes Control 15:921-929

20. Bonner MR, Han D, Nie J et al (2003) Positional accuracy of geocoded addresses in epidemiologic research. Epidemiology 14:408-412

21. Beyea J, Hatch M, Stellman SD et al (2006) Validation and calibration of a model used to reconstruct historical exposure to polycyclic aromatic hydrocarbons for use in epidemiologic studies. Environ Health Perspect 114:1053-1058

22. Beyea J, Hatch M, Stellman DH, Teitelbaum SL, Gammon MD (2005) Development of a traffic model for predicting airborne PAH exposures since 1960 on Long Island, New York. Report to the National Cancer Institute and the National Institute of Environmental Health Sciences for work completed under USPHS Grant U01-CA/ES-66572. Lambertville, NJ 08530:Consulting in the Public Interest. Available: http://www.cipi.com/PDF/ beyea2005trafficpahmodel.pdf [accessed 1 July 2005]

23. Li D, Wang M, Dhingra K, Hittelman WN (1996) Aromatic DNA adducts in adjacent tissues of breast cancer patients: clues to breast cancer etiology. Cancer Res 56:287-293

24. Li D, Wang M, Firozi PF et al (2002) Characterization of a major aromatic DNA adduct detected in human breast tissues. Environ Mol Mutagen 39:193-200
25. Rundle A, Tang D, Hibshoosh $\mathrm{H}$ et al (2000) The relationship between genetic damage from polycyclic aromatic hydrocarbons in breast tissue and breast cancer. Carcinogenesis 21:1281-1289

26. Gammon MD, Santella RM, Neugut AI et al (2002) Environmental toxins and breast cancer on Long Island. I. Polycyclic aromatic hydrocarbon DNA adducts. Cancer Epidemiol Biomarkers Prev 11:677-685

27. Palmer JR, Rosenberg L (1993) Cigarette smoking and the risk of breast cancer. Epidemiol Rev 15:145-156

28. Bonner MR, Nie J, Han D et al (2005) Secondhand smoke exposure in early life and the risk of breast cancer among never smokers (United States). Cancer Causes Control 16:683-689

29. Olson JE, Vachon CM, Vierkant RA et al (2005) Prepregnancy exposure to cigarette smoking and subsequent risk of postmenopausal breast cancer. Mayo Clin Proc 80:1423-1428

30. Li C, Malone K, Daling J (2005) The relationship between various measures of cigarette smoking and risk of breast cancer among older women 65-79 years of age (United States). Cancer Causes Control 16:975-985

31. Gram I, Braaten T, Terry P et al (2005) Breast cancer risk among women who start smoking as teenagers. Cancer Epidemiol Biomarkers Prev 14:61-66

32. Palmer JR, Wise L, Adams-Campbell L, Rosenberg L (2005) Cigarette smoking and risk of breast cancer in the black women's health study. Am J Epidemiol 161:S55

33. Cantor KP, Stewart PA, Brinton LA, Dosemeci M (1995) Occupational exposures and female breast cancer mortality in the United States. J Occup Environ Med 37:336-348

34. Petralia SA, Vena JE, Freudenheim JL et al (1999) Risk of premenopausal breast cancer in association with occupational exposure to polycyclic aromatic hydrocarbons and benzene. Scand J Work Environ Health 25:215-221

35. Brunekreef B, Janssen NA, de Hartog J et al (1997) Air pollution from truck traffic and lung function in children living near motorways. Epidemiology 8:298-303

36. Wyler C, Braun-Fahrlander C, Kunzli N et al (2000) Exposure to motor vehicle traffic and allergic sensitization. The Swiss Study on Air Pollution and Lung Diseases in Adults (SAPALDIA) Team. Epidemiology 11:450-456

37. Reynolds P, Von Behren J, Gunier RB, Goldberg DE, Hertz A (2004) Residential exposure to traffic in California and childhood cancer. Epidemiology 15:6-12

38. Visser O, van Wijnen JH, van Leeuwen FE (2004) Residential traffic density and cancer incidence in amsterdam, 1989-1997. Cancer Causes Control 15:331-339

39. Langholz B, Ebi KL, Thomas DC, Peters JM, London SJ (2002) Traffic density and the risk of childhood leukemia in a Los Angeles case-control study. Ann Epidemiol 12:482-487

40. English P, Neutra R, Scalf R et al (1999) Examining associations between childhood asthma and traffic flow using a geographic information system. Environ Health Perspect 107:761-767

41. Reynolds P, Elkin E, Scalf R, Von Behren J, Neutra RR (2001) A case-control pilot study of traffic exposures and early childhood leukemia using a geographic information system. Bioelectromagnetics Suppl 5:S58-S68

42. Hirsch T, Neumeister V, Weiland SK et al (2000) Traffic exposure and allergic sensitization against latex in children. J Allergy Clin Immunol 106:573-578

43. Beyea J (1999) Geographic exposure modeling: a valuable extension of geographic information systems for use in environmental epidemiology. Environ Health Perspect 107 (Suppl 1): $181-190$

44. Raaschou-Nielsen O, Hertel O, Vignati E et al (2000) An air pollution model for use in epidemiological studies: evaluation with measured levels of nitrogen dioxide and benzene. J Expo Anal Environ Epidemiol 10:4-14 